Why people say where they are during mobile phone calls.

Article submitted to Environment and Planning D: Society and Space

First submitted: October 1999

Revised: March 2000

Current word count: Approx. 10,000

Author: Eric Laurier

Address:

Department of Geography, University of Glasgow,

Hillhead,

Glasgow, G12 6QQ

UK

Address for correspondance:

3 Balcarres Street,

Edinburgh, EH10 5JB

UK

e.laurier@mail.qmced.ac.uk, e.laurier@virgin.net 


\section{Why people say where they are during mobile phone calls.}

Abstract: An often noticed feature of mobile phone calls is some form of 'geographical' locating after a greeting has been done. This article uses some singular instances of mobile phone conversations to provide an answer as to why this geo-linguistic feature has emerged. In examining two 'actual cases' and a vignette, some light is shed on a more classical spatial topic: mobility. During the opening and closing statements of the examination a short critique is put forward of the 'professionalisation' of cultural studies and cultural geography and their ways of theorising ordinary activities. It is argued that a concern with theory construction effectively distance them from everyday affairs where ordinary actors practically understand and competently account for what it going on in their worlds. This practical understanding is inherent in the intricacies of a conversational 'ordering' which is at one and the same time also an ordering of the times and spaces of these worlds. Choosing an indifferent approach to the 'grand theories' of culture, some detailed understandings of social practices are offered via the alternatives of ethnomethodological and conversational investigations. 


\section{Introduction}

\section{You're sitting on a train, you're tired and irritable after a long journey. Someone else's mobile phone rings. You hear it get louder as they fish it out of their bag. 'Hi' they say. There's a pause. 'I'm on the train. About half an hour away from London.' Why, you sigh, why do they always do that?}

In this article I will examine a feature of mobile phone conversations that I anticipate most people who live amongst mobile phones are familiar with - the giving of a geographical formulation as part of an opening sequence of a phone call. It is a feature which no longer seems as novel as it did even a mere five years ago now that mobile phones trill (often musically) for attention nearly everywhere where telephones were neither seen nor heard previously. As (Katz 1999) puts it: 'wireless communications shall cause frayed tempers and rude looks until there is social convergence about how to handle such situations' (p16). Despite its familiarity, one might say, taken-for-grantedness, we still notice when people say 'I'm on the train', 'I'm in a restaurant', often in spite of our desire to ignore its overhearability (and over-here-ability.) Such a familiar feature of language may be taken by many readers of a journal like Society and Space to be a dull, banal, irrelevant and, of course, irritating phrase not worth spending any longer than this introductory paragraph on. And yet it is precisely in such mundane and familiar geographical talk that we can find out how the world is socially and spatially organised (Schegloff 1972a) .

In what follows although I will be taking a "theoretical" attitude I will not procede as you might have observed others to do since I will not be doing Theorising as it tends to be done in cultural geography, sociology, cultural and media studies (Sharrock and Coleman 1999). So I will not be drawing together, sketching out or building a new and discrete theory from parts of the rich corpus offered by the social sciences nor using ethnographic material to complicate, fine-tune or build afresh a theory (such as a theory of 'the nomad' or 'the postmodern' or 'the public sphere'). Relatedly in handling my 'empirical material' that follows I will not be 'coding' or 'decoding' transcripts of in-depth interviews or focus groups carried out with members of some particular social or cultural group(s) as identified by terms such as 'working class' or 'gatekeepers' (Crabtree 1999). Not because terms such as 'working class' are inappropriate or ill-founded but because of more epistemic problems with the activity of 'coding' (Suchman and Jordan 1990). As a result I will not be interpreting and analysing those 'codes' and their related segments of text toward a previously worked out theoretical framework. And finally I will not be proposing an alternative or more complex theory to substitute any other social theory. My 'disagreement is not based on an alternative theoretical basis but on methodological grounds' (Crabtree, et al. 1998, page 6). In the shortest possible terms: I am interested in describing methods, in particular formulations of place (Schegloff 1972a), used by people who competently make and receive calls on their mobile phones day in, day out, as an ordinary, everyday (and sometimes annoying to bystanders) achievement. In what follows I will not be seeking to displace their methods and competencies in favour of the methods and competencies, as briefly described above, of doing what could be called theory driven ethnography. ${ }^{1}$ There may be times during the article when it seems that I am paying an excessive attention to detail yet you will have been offered an answer as to why people say where they are when called on their mobile phone that is versed through actual instances. Along the way we may also be able to observe some problems and topics which are often dealt with abstractly as problems for

\footnotetext{
${ }^{1}$ What Nigel Thrift (1999) might more elegantly specify as 'grand theory' ( see p297).
} 
a theory to solve, critique or remedy being handled as routine practical difficulties by a group of actors whose everyday business is dealing with such affairs (Sacks 1972b).

Of further interest to readers of Society and Space who may be having (productive) trouble with cultural studies and its related researches (and I would include myself here) running through this article will be an indirect critique of the growing professionalisation of cultural studies. A professionalisation wherein the lexicon of cultural studies claims have a kind of mastery of ordinary practices and in particular ordinary language and to be able to provide theoretical explanations for the orderliness of the world (Garfinkel and Sacks 1970). Members in and of particular places are treated all too often as 'cultural dopes' either by being shown to be victims of ideology or in more celebratory terms as being clever at resisting power or as performing (partially) the orderliness of whichever explanatory theory. Either way the locally accountable activities of members are subsumed in an often binary manner to the practices of theorising culture(s). ${ }^{2}$

The danger posed by the professionalisation of any field of social and spatial investigation is that the requirements of the performances of, for instance, 'doing competent cultural geography', miss the what, or haecceity, of socio-cultural practices which researchers attend (to) places to find out about (Garfinkel \& Wieder 1992). By the disciplinary standards it is wiser for a doctoral student with an interest in car-based tourism and 'nomadic subjects' in the USA to read Baudrillard's (1995) "America" and write an aridly amusing chapter on the European myth of the highway with some refinements to the concept of 'the nomad', than to consider travelling along with some French-speaking car-based tourists as they actually go about touring particular sites. ${ }^{3}$ Yet my case is still more strongly (ethno)methodological than requiring that students of social and spatial organisation should 'get out more' to learn how it is that their locals go about doing things. ${ }^{4}$ Human geographers, sociologists and cultural theorists would do well to stop substituting their professional methods for other members methods if they wish to learn from and not solely about their topics of interest; such as tourism and travel or in the case of this article: technology, mobility and conversation.

By formalising professional methods as discrete from the methods of the settings researchers are interested in we then proceed as if there were a set of constantly improvable standards for them, and simultaneously construct a technical vocabulary which applies and supplies to the profession its concerns and explanations. ${ }^{5}$ Standards and vocabulary which appear to exist independently of what happens during any investigation and can then be called upon for a priori judgements (Coulter 1983a) of whether such an investigation is, for instance, competent cultural geography. A policy of 'indifference' toward the social sciences as profession means re-placing their qualitative, quantitative or mixed methodologies 'amongst a vast field of practical activities in which methods are generated and used' (Lynch 1993, page 142). Further a general indifference to any social or cultural analysis which claims mastery, overarching critique or transcendence of social and cultural worlds means as Lynch puts it for sociology in particular:

\footnotetext{
${ }^{2}$ This is not exactly news and is a long running circular critique on a par with structure/agency, and is given an amusing and insightful treatment in (Morris 1998).

3 The constant proliferation of nouns prefaced by 'the' (frequently pronounced 'thee') such as thee nomad, thee body, thee real, thee rural etc. is an example of the replacement of everyday language circumstances, topics and resource by 'theorisations' from cultural geography's professional abstraction of these terms. An early critique of this 'boom' tendency and its movement toward banality in cultural studies can be found in Morris (ibid.)

${ }^{4}$ I use the term 'native' as (Lynch 1993) has drawn upon it from ethnomethodological approaches, to offer a quasianthropological sense of a member of a community or group and to make this term distinct from the term 'primitive'.

${ }^{5}$ Consider the multitude of increasingly arcane books on ethnographic research.
} 
'there can be no intelligible theoretical position "outside" the fields of practical action studied in sociology. Although this is an easy phrase to memorize and repeat, it expresses a lesson that is exceedingly difficult to take heart. Indeed, the lesson is continually subverted by one after another move into transcendental analysis.' (Lynch 1993, page 149).

Such an approach and such a critique of subjects that seek explanatory power over social life are not new by any means, indeed they are well, and better, rehearsed by ethnomethodologists and conversational analysts who have directed them at mainstream critical theory, psychology, sociology and linguistics for over three decades (Bogen 1999;) Coulter 1983b; ) Button 1991; Garfinkel 1967; ) Heritage and Atkinson 1984; Schegloff 1987; ) Schegloff 1992). Though it is a very worthy effort to present an ethnomethodological re-specification of the tasks and policies of, for instance, social and cultural geography it could easily occupy the space of an entire journal let alone an article. ${ }^{6}$ Instead I would like to investigate some actual talk-in-interaction similar to the scenario briefly described at the beginning of this article, as an attempt at an ethnomethodological and conversation analytic treatment of a 'setting' and its 'members'. By the explication of a setting and its members it is my aim to learn something about a classic social and spatial 'thing that they are up against and that they (the setting and its members) can be brought to teach the analyst what he (sic) needs to learn and to know from them, with which, by learning from them, to teach them what their affairs consist of as locally produced, locally occasioned, and locally ordered, locally described, locally questionable, counted, recorded, observable phenomena of order*, in and as of their in vivo accountable doable coherent and cogent detail for each another next first time' (Garfinkel 1992, page 186). ${ }^{7}$ One thing that I and other sociospatial researchers have been up against for several years (at least) is mobility* and how it is that nomadic groups of various kinds go about organising their lives across a multitude of places (Chambers 1993; Clifford 1992; Cresswell 1993; Gilroy 1993; Guattari 1992; Hastrup and Olwig 1997; Kaplan 1996; Massey 1994; Thrift 1996) also see the computer supported co-operative work (CSCW) collection (Dix 1996). There are all kinds of troublesome contingencies encountered in travelling while co-ordinating and organising actions that are not geographically proximate (Luff and Heath 1998; Suchman 1987). This is not to say that what is 'immediate' to a mobile human should be taken to be that which is within a simplistically described Euclidean space, but that such immediate people, devices, things and other stuff which are specific to the topology of that space (Mol and Law 1994). Which might seem a little abstract until we consider the case we are dealing with: someone speaking on a mobile phone. The overhearer of such a phone-call is less immediate to the activity of the phone call than either the caller or called. To use a suggestive phrase the two parties to the call are 'in touch' while the 'third party' overhearer is not.

To begin to offer an answer to the question as to why people say where they are, we need to shift focus from how an overhearer in everyday life responds to the hearable halves of a mobile phone conversation. We need to set aside that way of overhearing, suspend the "practical attitude" of everyday life with its practical concerns in order to follow with a "theoretical attitude" the unfolding of the telephone conversation as a social action which is organising mobility* and one that is available to

\footnotetext{
${ }^{6}$ A respecification of human geography in praxiological terms, which is highly sympathetic to the policies of Garfinkel, Wittgenstein and Sacks can be found in Thrift's $(1996$; 1999) ongoing critique of grand theory and representation (on Wittgenstein see also (Schatzki 1996) and a from a more artefact and learning perspective (Wenger 1998; )Engestrom 1990).

${ }^{7}$ Abridged explanation of that provided on page 202 of (Garfinkel \& Wieder 1992) for the use of 'order*': 'Spelled with an asterisk, order* is a collector and a proxy for any and every topic of logic, meaning, reason and order. ... Do no think, however, that ethnomethodology seeks out these creatures in order to settle them with them as topics of order*. Nothing of the sort. Rather, EM seeks to respecify them as locally produced, naturally accountable phenomena of order*'
} 
us as a recognisably standard line of action (Lynch 1997, page 9). The materials that I am going to work with are mainly transcripts of conversations, where at least one party to the conversation is on the move, but also related descriptions of a more variegated production, within which the conversations were situated. ${ }^{8}$ What I will attempt to show is how the talk that is occurring is a form of social action, that it has to deal with 'real-time' contingencies, that it is not explained by reference to an over-arching cultural theoretical context and that relatedly its sequentiality is key to its actions being done as happy and unhappy encounters which co-produce as part of their work an orderly time and space ( (Boden 1994; Drew and Heritage 1992; ) Thrift 1999, especially pp300-302).

\section{An everyday geographical problem solved everyday}

Schegloff (1972) produced the direct precursor to the work on 'locatings' that I am going to investigate wherein he collected forms of analysis which speakers use to accomplish the timing and spacing of events through everyday language. In his work he termed these analyses 'locational formulations' (Schegloff 1972, p79) and was building on earlier work by Harvey Sacks on membership categories(Sacks 1972a) which related to the identification of persons by the use of membership categorisations. In conversation analysis the work of categorising is an ongoing activity which can be made visible in strips of transcribed talk, though in the earlier work of Sacks the work of categorising is not restricted to talk. In a moment I will use the commonplace scene of a ringing mobile phone to draw out the distinctive way in which such categorising was dealt with by Sacks. In doing so I will thereby be rehearsing an argument made by Sacks (1974) on providing recognisable descriptions and the categorisations that tie actions and members together. ${ }^{9}$ However I will be adapting this argument in a slightly Latourian way to consider the characterisation of 'things' and the aforementioned sequentiality of activities that brings 'things' and 'people' into play (Latour 1992). A further adaptation I will be making is that instead of focussing solely on the text used by Sacks - 'The baby cried. The mommy picked it up.' - as the basis for examining membership categorisation, I will replay his succeeding observations on the pre-interpretative intelligibility of seeing and hearing. In doing so I will be turning to Sack's elucidation of what Lynch (1993: 226) calls 'an immense grammatical "cathedral" built up from a heterogeneous collection of simple devices. ${ }^{10}$

The familiar scene that I wish you to imagine is that you and I are sitting in a restaurant. All around us are diners that we have never encountered before. There is a ringing noise. I hear it as a mobile phone and I suppose that you hear it as the same thing. 'That's a first pair of observations' (Sacks, ibid., p224). ${ }^{11}$ After we hear the ringing noise in the restaurant, someone picks up a mobile phone. From what I have heard and what I saw: a mobile phone rang and its owner picked it up. And as before I

\footnotetext{
${ }^{8}$ Another way of describing the shift away in method from strictly transcript-based CA is to call what follows ethnographically-analysed transcripts (Moerman 1988), however I prefer to hold with the position of Michael Lynch (1997) on the margins of CA, where whilst not recognising myself as a conversation analyst I am certainly interested and sympathetic to its approach.

9 a.k.a. 'The baby cried. The mommy picked it up.'

${ }^{10}$ Cathedrals, as alluded to in the quote from Lynch, of the most complex forms were assembled via pre-drawn plans but only in a very restricted sense since they were elaborated and reflexively tied to the bricolage of compasses, rulers and string and thinking with their hands carried out by teams of builders and masons.

${ }^{11}$ The comments on pairs of observations from Sacks referred to hearing a baby crying, and then seeing that it is its mother that picks it up. Practitioners of CA would refer to this as a membership categorisation device (MCD) called a standard relational pair, e.g. mother-child, doctor-patient. For reasons stated earlier about the use of a marked distinction between professional 'technical' accounts and ordinary practical accomplishments, I would avoid substituting a professional understanding for a member's in the search for and mechanisation of features of practical reasoning (Button 1994).
} 
suppose that you heard and saw the same things. 'That's a second pair of observations.' (Sacks, ibid.).

Beginning with our first paired observation of a mobile phone ringing, it might be that the ringing was not the ringing of a mobile phone at all and that of a fire alarm but that is not the case. This much appears obvious, and it is the 'obviousness' that is important since hearing a ringing as a phone ringing is one of those actions that we do straightaway (or 'at a glance' as it is put in visual terms). Phones are available to us in that way, we do not have to ask one another 'what is that ringing noise?' ${ }^{12}$ It is worth adding, as Sacks might have, that there are other possible characterisations of the mobile phone as 'a designer plastic box with buttons' or 'a battery operated machine' or a 'a rental agreement between Orange and a customer' and Latour (1997) might offer these as a reminder of how the complex relatively stable accomplishment that is 'a mobile phone' is frequently forgotten by its users. On hearing what we have heard I think we would not say that 'a designer plastic box with buttons rang' if we could hear that 'a mobile phone rang', unless we wished to do something else in saying 'a designer plastic box with buttons rang'. The point to be made here is about the relations between the definition of a setting, actions within that setting and the identification of who is acting (i.e. 'the phone rings') by ordinary observations. Latour's version of such a scene would be likely to require the introduction of a telecommunications engineer to warrant an unusually detailed description of the agreements and heterogeneous engineering nesting in the space that we as ordinary observers would hear economically and consistently as a mobile phone.

Moving on to the second pair of observations, which are : when a telephone rings the person whose phone is ringing ought to pick it up (for the moment ignoring the all important possibilities of callscreening, people deliberately switching their mobile phones off and the slight differences between mobile phones and 'landlines' etc.) Incumbent on the person categorised as the owner of the mobile phone (qua telephone) is the duty to pick it up. If cultural theory focuses on this ordinary understanding as an issue of perhaps the technological imposition of a philosophical condition ('being on call') whereby it is incumbent upon those members who have a phone to answer it. Even if the answerer happen to be the philosopher Martin Heidegger and when he picks up his call it is the Nazi party on the other end of the line (Ronell 1989). Or to argue for technologically deterministic ends that: 'one higher order consequence of wireless communication is that it makes us more responsible, for both our own actions and those of people for whom we have assumed responsibility. In effect, we become more subject to social control' (Katz 1999, page 17), then cultural theory draws selectively upon any competent members' common sense knowledge of telephones to create a sense of their theory being 'real worldly' (Lynch 1993) rather than displaying the organisation of the social world which is the everyday problem of any competent owner or/and answerer of a telephone.

In his researches on the orderly features of telephony Harvey Sacks avoids constructing theories which make any claims to the 'mastery' of ordinary language whilst retaining a theoretical attitude by stepping back and bracketing the 'live action' to explicate the rules to which people orientate, and simple devices which are used to build 'bigger' chains. Drawing on Wittgenstein's investigations in rule following, he and subsequent ethnomethodolgists have retained an imminent critique of the rules as celibate entities : if there are rules then they are not found elsewhere than in their action and

\footnotetext{
${ }^{12}$ Although on the whole we immediately hear mobile phones as mobile phones since we have all gradually acquired competence in the hearing of mobile phones, when they first appeared this was not the case, and there were then often amusing moments when a ringing could be heard but hearers of the ringing (often including the answerer) were at a loss as to what the ringing meant (in terms of what they should orientate themselves toward). When one or the other of the parties figured out it was a phone then there would be some desperate fumbling in an attache case or handbag for the telephone and some degree of embarassment from the person who was supposed to be responsible for recognising and answering an electronic summons for their response.
} 
elaboration. Thus for a simple device such as sequential orderliness it has to be detailed just how it is put to use for those who are in that place, at that time. The two of us hearing a mobile phone ring and then its owner picking it up. What we have is a recognisable pair of observations, that a thing does something and that someone whose business it is to respond to that thing does so. As Psathas (Psathas 1999, page 145) puts it:

'1.) If a member sees a category-bound activity being done, then, if one can see it as being done by a member of a category to which the activity is bound, then: see it that way.

...

2.) If one sees a pair of actions which can be related via the operation of a norm that provides for the second given the first, where the doers can be seen as members of the categories the norm provides is proper for the pair then:

a.) see that doers are such members and

b.) see the second as done in conformity with the norm.'

Neither you nor I sitting in the restaurant feels the need to ask the person answering the mobile phone whether they are entitled to do so and whether it is not someone else's mobile phone that they are answering nor to ask each other what that person is doing, though of course we might want to express our irritation by saying some phrase including 'the invasion of technology into everyday life'. A highlytuned, logically coherent and critical theory of power is not brought to bear in and on this situation as it happens, nor does it sit as arbiter or guarantor on the telephone being picked up and our seeing the normality of such a sequence of actions. We might attribute the orderliness of what is going on as an example of mundane reason, but if, and only if, this were not to suggest that it does not require scientific or theoretical validation (Lynch 1996, p272). The 'correctness' of what has happened is observable and describable in the actual occasions of its activity. ${ }^{13}$

Such standards of correctness in seeing what happens in a setting as it is seen by a competent member are used by conversation analysts to hear and analyse (or, from transcripts; read and analyse) strips of talk. They offer the possibility via detailed analysis to recover or perhaps 'excavate', a machinery that organises everyday interactional events. The existence of this machinery is suggested by the 'prereflective way in which members hear utterances and act in accord with the "heard" order of events in a conversation' (Lynch 1993) p227. ${ }^{14}$

So far I have only dealt with the ringing and picking up of a mobile phone, which was mainly to further advance an investigation into the accomplished orderliness of a setting, whereas my main concern was with people saying where they are during a mobile phonecalls. One can easily imagine that such a statement might come next, and the question is why? Answering it requires, as claimed in the paragraph above, situating it in the "heard" order of events. At this point I would like to return to Schegloff's (1972) early and still unequalled work on formulating place where he hoped 'to derive some gains from some reflections on location-formulation selection divorced from conversational context' (p80). His pre-amble is revealing since it continues:

\footnotetext{
${ }^{13}$ Goffman(1956) and Sacks (1972) frequently demonstrate how this correctness can be 'incorrect' when it is exploited by fraudsters, con-artists and so on, it does not change the recognisability of what is going on and the possible description of such an event.

${ }^{14}$ It is not my aim in this article to articulate the careful critique made by Lynch of the professionalisation of conversation analysis and its misconception of what a natural science might consist of, yet I should state that his and other ethnomethodologists' critique of certain versions of CA has shaped my approach to describing the fine order and remarkable accomplishments of talk.
} 
'As I am proceeding here in explicit divorce from conversational context, I shall occasionally take a liberty not otherwise to be condoned of relying at various points on data easily enough recalled to have happened but not recorded and out of conversational context, or invented for the occasion.'

This statement says much about what 'data' is considered legitimate for conversation analysis and its reliance on audio-recording equipment to produce reliable and agreed-upon-for-the-purposes-of-CAinvestigations data. Yet just as soon as he has divorced itself from conversational context for the benefits of seeing the finely ordered work of everyday language on its surface, Schegloff invites a more generous sense of setting back into its analysis. This is not because language has to 'refer' or 'signify' to a 'place' (as in a 'restaurant' as a signifier represents a real place as a signified - so Schegloff would have to return to a context to check what the conversations are referring to) it is because they are mutually elaborative (or in terms closer to Schegloff's, topic is constituted by its formulation). ${ }^{15}$ Schegloff's problem is not one of exposing either the hidden ideological interests in how a place is represented or of providing an essentialist and explanatory grammar, it is of a more logical empiricist nature. ${ }^{16}$ 'How is it that on particular occasions of use some term from the set (of possible place formulations) is selected and other terms are rejected?' (p81). I will leave aside further presentation of Schegloff's analysis until the section below where the 'data' is presented. In sharp contrast to Schegloff I will leave my data 'married' to their 'contexts', in the setting which was mutually elaborated and extended via the acts of conversation. My reasoning for doing so is not only that my transcribed conversations were gathered during an ethnography so I have additional 'data' that I would like to use, it is more significantly because although a lot of what members do is accomplished through talk, that is not all they do and the accomplishment of their conversations is frequently reliant on and inter-woven with other practical accomplishments (such as being able to recognise the ringing tone of their mobile phone and differentiate it from someone else's).

\section{Nomadic workers saying where they are during mobile phone conversations}

As part of an ESRC research project I tracked down half a dozen people whose everyday business it was to organise their lives while being mobile. ${ }^{17}$ They were for the most part service industry employees, who spent normally between 3 and 5 days travelling from client to client in their company car and used a mobile phone with varying degrees of frequency. I spent at least a week travelling around the highways and byways of various regions and territories, and generally hanging around in an unmotivated manner with each of these mobile workers. My method of learning about the organisation of their work is similar to the training given to new staff in their sectors who ride around with

\footnotetext{
${ }^{15}$ In Hinchliffe's (1996) meditation on technology, a similar point is made about 'technological' objects, in that they exist as they are constituted and there is no sovereign object which exists without constition in some event, in Hinchliffe's case, as in this one, a documentary event.

${ }^{16}$ Schegloff has written several powerful critiques of grammar as used in a non-Wittgensteinian sense by linguists such Searle and Chomsky (i.e. (Ochs et al. 1997))

${ }^{17}$ Mobile workers are frequently referred to at the time of writing as 'road warriors', though during the research period I never heard this term used as a description. And I am not fully sure what I make of the term, apart from that employees of companies that go 'on the road' are involved in some kind of 'Mad Max' struggle to survive which does offer a certain kind of romantic if dystopian imagery to their working environment.
} 
experienced staff before going taking on responsibility for the job themselves. During these short passenger-seat ethnographies I gathered, amongst other materials, some 'specimens' (Alasuutari 1995) Have 1998) of these workers saying where they are. ${ }^{18}$ An obvious weakness in my account of organising work over the phone from an ethnomethodological perspective is that I could not pass as a competent member of the staff of those organisations whom I studied and thus I am not competent in instructing others in how such a job might be done. ${ }^{19}$ However the ambitions of my project here are not so much to describe their work as part of some (large) institutions in action (Boden 1994) (Psathas 1999) as pick out and make visible an orderly feature of their talk which occurs in many settings which involve mobile phones.

The first specimen we going to look at involves Penelope, who is a personnel officer for a substantial and expanding transportation company which has offices across the UK, talking with Sharon her PA. Penelope and Sharon have to work 'closely' together despite the fact that Penelope spends most days of the week visiting the local offices of their company which are spread across the South of England. Sharon on the other hand stays permanently in 'Penelope's' office at the company headquarter answering and screening calls for her, dealing with incoming mail, filing and other tasks.

\section{Specimen 1: The relevance of Avonmouth}

((Penelope Barley (P) dialing her PA Sharon (S) from mobile/car phone with audible bleeps, then waiting to speak 'hands free' while driving along dual-carriageway))

S: >Penelope Barley's $<$ office. Good morning.

P: Good morning, Sharon. It's Penny ((said in a slightly higher voice, almost joking)).

\section{S: Hello ((happily))}

$\rightarrow$ P: ((continues joking voice)) I'm heading to Brisle ((Bristol)) ((returns to 'normal' voice)) to Bristol, that's where I live, back to Avonmouth.

S: (s-pause) Oh are you ((still happily))

\footnotetext{
${ }^{18}$ Harvey Sacks at the outset of conversation analysis suggested that it was a primitive natural science, in that like early kinds of geology, biology or astronomy it could be verified by an observer going out into the field and re-doing the observation or finding and examining an equivalent 'specimen' in Alasuurti's terminology (see (Sacks 1992a p81-91) (Lynch and Bogen 1994)). Given Lynch's (1993) critique of Sacks' version of natural science I am wary of making such a claim, and would alert the reader to the equipment and training necessary to redo my collecting and that equally it is not characteristic of natural science to actually replicate experiments in the way suggested by Sacks. Nevertheless I value the sense in which specimen collecting as a primitive method for social researchers re-unites it with natural science practices, even if it is to some extent inevitably reductive it also allows for amplification (Latour 1999) and in a more prosaic sense it is a way of delivering some 'news' to other researchers (Lynch 1993).

${ }^{19}$ Though I am highly sympathetic and consistently impressed by the investigations of conversation analysts, I am also wary of claiming that I have achieved adequate descriptions of what is happening in the following transcripts on the basis of having audio-tapes of a conversation that I can re-listen to or share with other researchers since as (Crabtree 2000) puts it: 'That machinery (CA procedures) is a construction of the professional analyst's work, not ordinary members' work. It is only available to the professional analyst (which is a rather serious state of affairs for persons said to be concerned with naturally occurring social interaction, not least because if the machinery did exist then members must, as matter of course, be fully familiar with it and its workings)'
} 
P: And then I'm gonna go up to Berries, yes, so::: uhm::

$\mathrm{S}:=\mathrm{Oh}$ right, okay (see) Steve Appleton wants a word with you

P: Yeah, I'll give him a ring when I get to Avonmouth, [he's left me a note].

$+$

S: [That's a'right] $>$ I didn't know whether he left a message or not $<$. He's in Borchester all day.

P: Yes he left one last night he left one [this morning] ((sounds irritated))

S:

[Oh dear] and Paul Barber was after you as

well.

P: ${ }^{\circ} \mathrm{Oh}$, that's all right (then) ${ }^{\circ}$. Uhm:::

$\mathrm{S}:=$ about the letter

P: ${ }^{\circ}$ Yeauh $^{\circ} \mathrm{I}^{\prime} l 1$ do that when I get to Avonmouth

S: Luvely.

Watching Penelope dial I was struck by the fact that she only had to look for a moment when reaching out to dial. Once her hand had found the keyboard of the phone, she was digitally accomplished in that place, in that she kept her eyes on the road in the way that a practice classical pianist can keep her eyes on the music sheet rather than the keyboard (Sudnow 1978). ${ }^{20}$ These observations aside for the moment, if we follow the transcript of the ensuing conversation, then, it has by the fourth utterance turned up an instance of the feature I am interested in: 'I'm heading to...' ${ }^{21}$ It is an example of what Schegloff (1974) calls a 'locational formulation' and it begins the task of trying to successfully coordinate the work of Penelope Barley who is driving her car with Sharon, who is staffing Penelope's immobile office. For Penelope and Sharon to co-ordinate their affairs then, some sense of shared context has to be accomplished by them, and this was more apparent to me precisely because mobile telephony was rendered it difficult for them to interact with one another.

As (Tolmie et al. 1998) put it:

\footnotetext{
${ }^{20}$ In Sudnow's remarkable investigation of jazz piano playing, he frequently uses the more everyday example of driving a car to assist non-jazz piano playing readers in grasping what it is to be a competent jazz painist.

${ }^{21}$ However I am not suggesting that this instance be pulled out of the flow of conduct that it occurred within to be used in a representational manner, such as, for a comparison with several dozen other representative instances, interesting though such a comparison may be (i.e. (Schegloff 1972b; ) Schegloff 1979)). Indeed the 'plucking' (or 'cutting' as De Certeau (1984) puts it) of the brightest feathers (which the fourth utterance would hardly qualify for) from transcripts is part of the method of 'coding' as used by numerous 'qualitative' researchers (see me doing it: (Laurier, et al. 1999) and for another example (Huberman and Miles 1998)). It is a method institutionalised in such social science software packages as NUDist, nVivo, ATLAS and Winmax (i.e. Richards and Richards 1998). It is a method ideal for the doing of, for instance, 'professionalised cultural studies' since one of its next instructions would be to seek ways of generalising from this instance, in an analytic search for its relation to a semiotic structure, cultural formation or other abstractive or systematising theory, and if not that, then perhaps the catch-all explanation 'context'.
} 
The sense each party to the interaction has, then, of there being some locatable set of relevances which they share, is not something simply taken for granted and put to one side. Instead it turns out to be something that they have to work at recurrently throughout the conversation. A good deal of this work is informal, light-hearted in character, and redolent with personal details. Work of this order has been characterised elsewhere as 'demeanour work'(King and Randall 1994; Randall and Hughes 1994).

Returning to the transcript, we can see that the greeting offered by Sharon is of a particular kind, it makes available several things, firstly, that the caller has successfully been picked up at the other end by someone who the caller may or may not be trying to 'reach'. Secondly that this answerer is indicating they are answering for and thus enacting an institution (Boden 1994), since instead of using the highly standardised 'hello' greeting on the phone, they say 'Penelope Barley's office. Good Morning.' Thirdly that they are doing some further locating within this institution by identifying the particular office and name of the person for whom they are acting as the answerer for, in this somewhat unusual case they are the answerer for the caller. Penelope's greeting in return identifies her to her PA. The saying of her name rather than just 'hi' (or a similar greeting) we could take as indicating that she is not risking the playing of the 'voice-recognition game' with her PA whereby the sound of her voice should be sufficient to identify Penelope to Sharon (Sacks 1992b, p161). However with the benefit of additional field observations of the audibility problems of hands-free mobile phones not available from the transcript, I would suggest that it is also a function of the poor signal quality on mobile phones where voices are often highly distorted, and the game of identifying someone purely by their voice might be played as a test of the ability to pick signal out of noise rather than a known caller from an unknown caller. Once Penelope has identified herself to Sharon, then Sharon redoes her greeting with a warm recognition. In this way by juxtaposing her warm, if brief, 'hello' with the more 'institutional' greeting that she initially offers an unknown caller she is doing 'demeanour work'.

One of the other properties of telephone calls which has been highly commented on by Sacks (i.e. $1992 \mathrm{~b}$, Lectures $1 \& 2,1970$ ) amongst others is the distinction between caller and called. There are a collection of understandings affiliated with this distinction, one of the most significant being that it is the caller (unless they are 'calling back') that has some kind of 'first topic' to raise. They have a reason for calling, which at some point has to be brought up and might be expected to be the next action in a sequence after a greeting has been done. How greetings are finished with is an interesting issue in itself, but not one that we will cover here (but see, (Schegloff 1972b). When Sharon redoes her greeting she does not set the first move for any kind of next action, which, for example, she could have done by saying: 'Hi Steve Appleton called for you' (though she does raise that matter later). The next utterance, the locating turn, involves a mistake from Penelope and then its immediate repair: she is not going to Bristol, she is going 'back' to Avonmouth. Building on Schegloff's (1972) locational formulations, the point that I am going to try and develop is that the selection by Penelope of 'Avonmouth' (or various other locations given during mobile phone calls) are relevant locatings that lead on from earlier events and work toward ordering what will happen next.

Given that Penelope calls Sharon at 'Penelope's' extension every morning as she sets off to her first destination in her car, unless she is actually going to 'the office' to join her there, they have this temporal ordering available to them already. To clarify the difference this makes, we need only consider what happens when someone calls you that you have not heard from for a long time. When this person calls you, you can guess that they are not just going to tell you their day's mundane news, as 
they might to some friend they telephoned on a more regular basis. They may announce they are phoning 'just to catch up' or 'or to see how you were' and if they do not do this, or even if they do, you will expect there to be some more significant topic like an arrangement to come visit, some piece of 'big news' they are offering (i.e. a birth, death, new job, new house etc.) as a reason for calling (Sacks, 1992b). Although Sharon is the called she does not have wait to hear Penelope's reason for calling (as the caller) - they are speaking to one another because they do this day in, day out to co-ordinate their day's activities. Apart from making this temporal ordering available to them it thus also blurs the caller/called distinction. So with a temporal ordering available to them what further remains to be organised are their spatial relations. In the sequence of hearing, both Penelope and her PA have it available to them already that the PA is in Penelope's office answering the phone. In fact the PA's location is potentially available to Penelope from an even earlier non-verbal action, which I will leave examining till later in this article. In contrast Penelope's work is not sedentary, she is generally in her car at the time in the morning of the call, sometimes she is at a branch office, sometimes she is at home, so further locating is required. It is also worth noting that Sharon keeps Penelope's diary and so does already have access to a textual indication of where Penelope should be. Nevertheless Penelope's immediate plans can be changed to respond to various requests from her company at very short notice and equally she has the discretionary power to cancel appointments and re-arrange her agenda overnight. And of course for people travelling by car for extended periods there are all kinds of other contingencies such as flat tyres, traffic jams, diversions, getting lost etc. By saying that she is on her way back to 'Avonmouth' Penelope is confirming that she is following her diary and she is formulating a location, which she further shapes by adding her next destination. The organising of mobility* that 'Avonmouth' is doing is not yet sufficiently described since Avonmouth, even though apparently what Schegloff (1972) would classify as a 'G term' (meaning geographical), is further known to both Penelope and Sharon as one of their company's major regional depots. Once more this may seem trivial, until we consider how it is made relevant, it is part of the category of company branch offices or what Schegloff would classify as an ' $\mathrm{R}_{\mathrm{m}}$ term' (relation to members). There are a variety of spatial formulations that Penelope could have used such as a $G$ term like 'the County of Avon' or an $R_{m}$ term like, 'Bob Smith's office' or am ' $R_{1}$ term' (between places) such as 'I'm travelling North on the M5' (see Schegloff 1972, pages 97-99). Some of these locations might require clarification from Sharon, such as if Penelope were travelling on the M5 had she been to 'Avonmouth' already or did she have to change her diary appointments for the day. Other references would begin to do other kinds work, since if Penelope said she were going to Bob Smith's office she would be suggesting that there may be one specific purpose ('Bob Smith') for her going to their regional office to which attention should be paid (i.e. Bob Smith by being mentioned had been made relevant). The wider possibilities of what can be done at 'Avonmouth' (as against Bob Smith's office) become clearer in the actions that are proposed in the subsequent utterances, since Sharon passes over the names of 2 people with associated problems and Penelope says that she will deal with them when she gets to 'Avonmouth'. The name of this small town in the South West of England is thus knowable to these 2 co-workers in a certain way, which is not to imply that the job of cultural studies or cultural geography is to provide a 'contextualisation' that when Sharon and Penelope say 'Avonmouth' what they really mean is 'some other employees that Penelope has to see and also a telephone, desk and computer at the regional office in the dockyards about fifteen minutes by car from Penelope's present position' (and this substitution of cultural longhand for ordinary shorthand could get bigger). This kind of remedying of an indexical term which produces a more proper interpretation of 'Avonmouth' is the all too frequent activity of cultural geography and is indeed a potentially infinite one (Garfinkel and Sacks 1970). In their use of 'Avonmouth' (or other locatings even more indexical such as 'here' or 'there') parties to a conversation are using terms that have an orderliness to them (which does not need to be (retrospectively) interpreted for them) and that the establishing of these orders 'is an ongoing, practical accomplishment of every actual occasion of commonplace speech and conduct'. (Garfinkel \& Sacks 1970, page 341; Bittner 
1977). Nor do they need what they are talking about 'theoretically' explained back to them since they 'know' what they are talking about for the practical purposes they are engaged in. ${ }^{22}$

\section{Specimen 2: 'Where are you today'}

In the next excerpt both the parties to the call are mobile workers and we can see in a relatively obvious way, given the earlier investigation of Penelope and Sharon's call, how a spatio-temporal context is being mutually accomplished. What is significant in what follows is that not one but both parties to the call are nomadic workers using mobile phones :

((Sylvia dials up Ernie's number on her mobile keyboard, it makes audible bleeps, then a ringing tone begins))

E: (Hello it's Ernie)

$\mathrm{S}:=$ Hi Ernie, it's Sylvia

E: Hi Sylvia, how ya doin

S: I:'m all right. Where are you today

E: Ehm I'm in London at some point once the trains start running properly

S: (s-pause) Have you got problems on trains $\uparrow$

E: Big time problems (s-pause) Ehm uh there's track lines down at Stevenage an::d Welwyn Garden City so we've been standing here for about Christ knows how long [jus' waitin' on a train] into London.

$+$

$\mathrm{S}:[\mathrm{Aww}]$.

E: So all fun and games. $>$ How where are you today $<\uparrow[. h h h]$

$\rightarrow \mathrm{S}:$

[Well] I'm gonna be in London for a

short while today.

E: [aw right]

$+$

S: [I've] got a whole load of stuff I've just picked up from Kingswood for you $>$ I was gonna work in Kingswood today < but I've decided to go and I wanna see Marc and do a couple of things for tomorrow

\footnotetext{
${ }^{22}$ Ethnomethodology sits, spiked, on the horns of this dilemma since it is frequently accused by the groups it studies such as variously lawyers, astronomers, bankers and piano players, of offering back to them exactly what they knew already. And accused from the social and cultural studies side by audiences used to either 'explanations' or 'theory construction' as offering mere (and very lengthy) descriptions of phenomena that are obvious.
} 
In this second excerpt we can see a lengthier locational formulation, as Ernie depicts his current, and by the close of the excerpt - relevant, troubles with trains. Indeed this may be just the kind of account that many of us, who have not uttered it ourselves on a mobile phone, are very likely to have overheard. Also neither Ernie nor Sylvia have each other's locations pre-established since not only are they both known to each other as nomadic workers and thus lacking "base places" (Schegloff 1972, p98), they are also not in possession of a shared space-time text (i.e. diary) as Penelope and her PA were. Yet Ernie and Sylvia were part of the same work team, which had its regions spread across the UK, so they were in frequent contact with one another to co-ordinate a variety of activities. The 'closeness' of the collaboration was not normally of the same degree as Penelope and her PA since Ernie dealt with the South West of England while Sylvia dealt with the South East. However, Ernie was soon to be taking over Sylvia's region, and the phone call takes place during a period when Sylvia was 'handing over' her region to Ernie and thus they were attempting to meet face-to-face as often as they could.

The features picked out with the arrows are where London is mentioned, amongst another local geography of 'known' locations of their institution (i.e. 'Kingswood' - a regional office). Ernie brings up 'London' in the fifth utterance of the sequence, though in this instance as a second-pair part (i.e the response part of: question/response) to Sylvia's question, 'where are you today?' Much like the use of a local order such as place names within a company, the term 'today' does not mean literally the $19^{\text {th }}$ of September 1998, nor the 24 hours that lie within that calendrical date. 'Today' is used for the possible local relevancies that Sylvia and Ernie can produce (see also Sacks 1992b, Lecture 1, 1970, p172). So Sylvia would be surprised if Ned were to begin with his intention to go to sleep at $10 \mathrm{pm}$, or equally to ask Sylvia, what did she mean by 'today'? If he did either of those things as a response to her question we might figure that he was trying out a joke, being evasive or possibly suffering some form of mental illness. 'London' is a recognisable name for a location because the main office of their multi-national company is there and Sylvia and Ned have met there several times already to organise their 'hand-over'. London is thus heard by both members here to be name of their office and not a general name for the whole greater London area and it is by using such locational formulations that Sylvia and Ernie display their membership of the company, as Schegloff (1972, p93) puts it:

'It is by reference to the adequate recognizability of detail, including place names, that one is in this sense a member, and those who do not share such recognitions are "strangers".'

Once he has begun formulating London as the place in which his mobility is in relation to, he works out the contingencies attached to his arriving there 'at some point' and attributes this contingency to 'the trains'. In her next turn Sylvia asks another question, one that is clearly a 'response' to Ernie's previous response, which whilst asking a question is also showing that she has taken note of Ernie's problem. In other words the conversational 'chaining effect' running from utterance to utterance includes the askingof-a-question even if we might want to treat that question as a sovereign statement, it has to make sense of and make sense in its sequenced setting of use. In this way questions as they are asked in everyday life can seem apposite, tactical, amusing, unsolicited, inappropriate, hostile, rhetorical or even superfluous ('need you ask why?') and most importantly rely for their sense on their location in an unfolding conversation where the response will retro-fit the earlier 'question' (Schegloff 1978) (Button 1994) As we can see in Sylvia's turn: 'Have you got problems on trains', her question, has in a sense been elicited by Ernie's '.. at some point once the trains start running properly'. Ernie's initial statement is therby providing for Sylvia's question and tailoring the (re)turn after her question for Ernie to provide a somewhat lengthy account of why he might not be able to say when he and Sylvia can meet up. 
What happens next is intriguing since Ernie now produces what we might take to be a very noticeable complaint or piece of trouble talk - he says 'Christ knows how long', which in its audible state is hearable as somewhat resigned. Sylvia chimes in sympathetically with her overlapping 'aw' and thereby shows that she is both accepting and 'sympathetic' to Ernie's troubles (she is after all a 'fellow traveller'). Ernie is giving in one sense a straightforward piece of relevant information to Sylvia as to what is causing him to be delayed. This relaying is done in an elegantly delivered form, and rightly so, since if it is elegant enough in its delivery as 'railway transport trouble' then Sylvia may well re-tell it later. Ernie handles his 'transport trouble story' with expertise, invoking the double trouble of railway track being inoperative in two different places and the commonly known and categorically negative experience of standing waiting endlessly for a train that never arrives. Why Ernie might attempt to turn his troubles into a tellable event requires us to consider the consequent institutional problems that nomadic workers frequently face. Since if Ernie's trains do, ultimately, deliver him late to London, and he then misses or delays a meeting with someone else at the multi-national, he is risking, by his not turning up on time, being attributed to the class of people at work known for 'being late' ${ }^{23}$. This is a 'big time' contingency in doing mobility* since, as noted earlier, travellers constantly face traffic jams, possible flat tyres, delayed trains etc. and so each actual occasion of lateness requires careful accounting for in terms of these recognisable explanations, less the person becomes known as someone who is 'always late'. How someone becomes known as a tardy individual is in part through such actual moments as when one of his colleagues says to the other 'Ernie's late for this meeting' and they say 'Ernie's always late', and no one defends Ernie's reputation, and indeed colleagues can go away from the meeting with a 'choice piece' of work gossip to tell other people at the office (Sacks 1992b, p44, 'Complaints about interruption'). After only a few such occasions Ernie's reputation as an untimely person can be passed on as part of his 'personality' for the purposes of the multi-national and he may well have to work very hard to change this memorable aspect of his office personality since whenever people at the multi-national have to meet him they will tend to look for confirmation of his lateness. To offer a mild disaster story over the phone to Sylvia with some details about 'track lines' and place names, a tone of resignation and irony ('all fun and games') is to offer a neatly packaged account to someone that will be at headquarters with Ernie's colleagues when Ernie's lateness is remarked on and thus be able to give an account on the basis of this memorable defence, for Ernie-at-a-distance, to prevent someone else saying without contention that 'Ernie is always late'. For Sylvia to give such a substantiated defence is in her interest as well since as nomadic worker she does indeed face the same problems of timing as Ernie does and her giving an account of his lateness also makes the constant problems of travel a 'commonly known' thing amongst the 'non-nomads' at headquarters. Sylvia is thus, as a by-product, safe-guarding the general reputation of a class of people at her workplace who are doing mobility* and may be known as 'people in the field', 'the salesforce' etc.

After Ernie has finished locating himself, he hands over the floor for Sylvia to do the same. What you may or may not have noticed is that if we were now to ask ourselves could we or Sylvia have driven our car to find Ernie, the answer is no. We know a bunch of things that are relevant to trying to meet him in London later in the day, but as to where he is, as of that moment, as he says he is 'standing here'. Unless he does need collected or some further immediate assistance, 'here' is an economical and appropriate solution. For the overhearers standing beside him they know very well what situation he is

\footnotetext{
${ }^{23}$ Sacks (1992b) in Lecture 4 1968, p52-55 provides a remarkable analysis of how specific cases of interrupting can be transformed into the class 'being rude' and how people with an interest in maintaining a good biography will attempt to avoid being categorised by anyone else as being rude, and that this provides for an enforcement system for turn-taking in conversation and much else besides. In a parallel way I am attempting to show equally why a singular case of missing a meeting can if not worked upon by Ernie end up in his biography, as it is passed around by his colleagues at the multinational, suffering.
} 
refering to.

Where We Began

\section{I'm having lunch outdoors on a terrace cafe during a break while writing this paper, someone's mobile phone rings. It's a long-haired woman at the next table. She picks it up and after it beeps she says, hello. There's a pause and then she says happily, I'm sitting having lunch on a sunny day in Edinburgh.}

Even in this vignette it seems reasonable to suggest that the answerer's locational formulation is setting up some kind of mutual sense of her 'context' and of what may be relevant to her as an answerer in such a context. All my earlier specimens dealt with 'work' calls, and yet one of the tricky aspects of context that has to be established during a mobile phone call is often whether the answerer is, for the purposes of the caller, at work or not. 'Landline' phone numbers are listed as work numbers and home numbers, when a caller dials a number, one available ordering in the 'pre-beginning' to the call, is generally whether they are dialing the called's work number or their home number. ${ }^{24}$ This simple division into two phone numbers has all kinds of implications about who the caller can expect to be overhearing the call at the other end, how long the call can be, what it might be interrupted by. When Penelope calls her PA at her office number, for instance, she knows the place she is calling as an organised space where numerous insituional resources are stored and can ask for a file to be pulled out of the filing cabinet and read back to her over the phone.

A mobile phone apart from its possibilities of being picked up in all manner of situations by its answerer, also often lacks definition as to whether its answerers consider themselves to be in their working hours or not (see also (Katz 1999). When the woman in the vignette picks up her phone and says where she is, one of the clues she may be giving her caller is that she is as available as we would judge someone mid-lunch on holiday to be.

In Schegloff's (1972) description of locational formulation of the 'X type', such as significantly 'the office' or 'my home', he suggests they have a special character in that not only are they understood as 'belonging to' someone (i.e. Penelope Barley's office), equally 'such a place is for a member "where he or she belongs" (i.e. one can reasonably call there without having to account for why one is looking for them there). In practical terms when making a phone call, a stranger to the caller can still respond with a phrase such as 'she's out right now' or 'you must have a wrong number' by knowledge of the people who are related to the place which is being connected to by telephony. What mobile phones bring is a loss of the tie between place and member, which perhaps goes some way to seeing why it is that one member seldom answers another's mobile phone, since the caller is expectably not calling a place but a person, and an answerer will have to account for why they are picking up the phone, without recourse to a phrase such as 'she's not here right now.' Since the 'here' is no longer clear to either party as to where it is.

\footnotetext{
${ }^{24}$ There are numerous home workers whose home phone number and work number will be the same, and who will therefore have to manage just such issues as: whether they will have formulate at the outset of the conversation their availability for either personal calls or work calls.
} 


\section{Conclusion}

Context, in the form of 'social context' or 'cultural context' or 'economic context' and so on, is often used as an explanation for why an event occurs or why actors do certain things. Claims to provide contextual explanation supply their disciplinary expertise as either cause or container (the latter is what (Drew and Heritage 1992) amusingly term: the "bucket" theory of context). When the term 'context' is used by conversation analysts and ethnomethodologists it is not to refer to theorisable pre-existing zeitgeist but rather a setting reflexively tied to unfolding action, or equally lines of action tied reflexively to an unfolding setting. As Zimmerman (1992) puts it:

Since context functions to foreground and activate pertinent knowledge and skills and to provide the situated sense and relevance of these activities, it must in some sense be "available" to participants in these activities, then and there. The availability of context is found precisely in the ways in which the participants make locally observable and accountable for one another such features of their current activities.' (page 36).

In a brief examination of requesting a mobile phone number from someone, Katz (1999) points out that it can be emotional issue since depending on whether it is obtained or not, its proffering can be an assessment of mutual worth and a potential moment of embarassment. Whilst I would certainly agree that obtaining someone's phone number be a moment of careful negotiation, and more so with a mobile phone because it no longer carries a member's categorisation such as 'the office'. In relation to the quote from Zimmerman above its status as a mobile number is important to the person that is going to use it because it needs to be recognised as such - thus it often has 'mobile' or ' $m$ ' written beside it - and is further recognisable by its numeric arrangement (i.e in the UK when reading the digits from left to right it does not begin '01'). Knowing at the outset whether one is calling a mobile phone or not, as I hope this article has made clear, is not just to do with a caller's concern with the call charge rates they may be incurring when connected via a mobile network but is because it shapes the character of ordinary geographical work that will need to by both caller and called. The act of finding a mobile phone number as a mobile number forms a context for what will and might happen next.

Although I seemingly promised an explanation as to why people say where they are during mobile phone calls I hope it has become apparent that there is not one answer and there are good reasons for being wary of social and cultural theories that claim to provide themselves as an explanation. Whilst suggesting that there are one or more answers, in the form of displays of the grammar of everyday life, as to why, or perhaps, how people say where they are, it is still possible and important to turn to a 'classic theme' from human geography, cultural studies and cultural geography in order 'to break out of the academic literature (Lynch 1993, p300). In my research the particular topic of the current situation of academic inquiry which fed my own project was mobility* and so I went is search of a setting in which it played a prominent 'vernacular role' (Lynch, ibid).

In learning from the practical achievements of nomadics workers I left the classic theme of mobility* as an unexplicated term for social phenomena which are investigable in their actual local productions of order (Garfinkel 1992). Post-analytic ethnomethodology has been a called a 'post-graduate' form of study for researchers by Lynch (1993) since it still requires a basic familiarity with what the 'classic 
themes' in human geography, cultural studies, sociology, politics, science studies or any other discipline are. It offers a post-Enlightenment path for continuing such investigations by re-mixing their professional concerns with the ordinary practices which they seek to master. ${ }^{25}$ Part of what such investigations offer is a praxiological turn, which may well be a refreshing twist away from a textual foundationalism that inadvertantly can accompany a literary/cultural turn.

As I noted at its outset this article could have consisted of a lengthy depiction of what I think, for instance, cultural studies consists of as a set of literatures and approaches and so on, and then an equally lengthy depiction of what my picture of conversation analysis or ethnomethodology are. Instead of such an approach I have tried to do some re-specifiying in an ethnomethodological mode whilst also 'doing' some investigation of some feature of ordinary practices which most readers will have noticed. This is a way of explicating pursued by Harvey Sacks in his lectures on conversation (which I have borrowed on heavily for my description of what is going on during the two strips of talk transcribed in this article) and also by Wittgenstein in all of his later works. Emanuel Schegloff (1972) carried out the most exhaustive and encyclopaedic analysis of 'locational formulations' in conversation and I have struggled to show the difference mobile phones make to his analysis, and moreover to replace the technical concerns of his profession with ordinary members. Both of Sacks and Wittgenstein, by slightly different means, were pursuing the description of language-in-use as a way of displacing the 'big time problems' of high theory into the 'big time problems' of ordinary practices.

The more narrowly we examine actual language, the sharper becomes the conflict between it and our requirement. (For the crystalline purity of logic was, of course, not a result of investigation: it was a requirement.) The conflict becomes intolerable; the requirement is now in danger of becoming empty. -We have got on to a slippery ice where there is no friction and so in a certain sense the conditions are ideal, but also, just because of that, we are unable to walk. We want to walk: so we need friction. Back to the rough ground!

108. (Wittgenstein 1953, page 46)

${ }^{25}$ An exemplary study being Sudnow's (1978) study of jazz piano playing through jazz piano playing, tutoring and the documentation of the haecceity of this embodied doing. 


\section{Acknowledgements}

I would like to recognize the remarkable responsiveness and critical attentiveness of Professor Chris Philo on our socio-spatial and technical research project on cars and mobile phones, of which this paper is part of the analysis of. The project was undertaken with funding from the ESRC (Grant No R000222071). The ideas and views expressed in the article are those of the author and are not necessarily those of the funding body. A greater than usual debt is owed to the co-participants in these two research projects, most notably 'Sylvia' and 'Penelope', from whom I have learnt a great deal about mobility* and hospitality. For her enthusiasm, engagement and willingness to listen to very long descriptions of how to recognise a phone ringing I must thank Gillian Rose (who also provided a lovely 'thee body' anecdote). For their practical concerns with window ledges, sleep and rodents: Spunky and Lola. 


\section{Bibliography}

Alasuutari P, 1995 Researching culture: qualitative method and cultural studies (London: Sage)

Baudrillard J, 1995 America (London: Verso)

Bittner E, 1977 “Must We Say What We Mean?", in Communication and Social Interaction Ed P F

Ostwald (New York: Grube \& Stratton) pp 180-197

Boden D, 1994 The Business of Talk (Cambridge: Polity Press)

Bogen D, 1999 Order without rules: critical theory and the logic of conversation (New York: State University of New York Press)

Button G, 1991 Ethnomethodology and the Human Sciences (Cambridge: Cambridge University Press)

Button G, 1994 "Going Up a Blind Alley, Conflating Conversation Analysis and Computational

Modelling", in Computers and Conversation Eds P Luff, N Gilbert and D Frohlich (London:

Academic Press) pp 67-90

Chambers I, 1993 Migrancy, Culture and Identity (London: Routledge)

Clifford J, 1992 “Travelling Cultures”, in Cultural Studies Eds L Grossberg, C Nelson and P A

Treichler (London: Routledge) pp 96-116

Coulter J, 1983a "Contingent and a priori structures in sequential analysis" Human Studies 6 361-374

Coulter J, 1983b Rethinking Cognitive Theory (London: Macmillan)

Crabtree A, 1999 "The category 'woman' as natural language category in everyday life: respecifying the exploited category 'woman'.", (Lancaster: University of Lancaster) -online paper -

http://www.comp.lancs.ac.uk/sociology/TeamEthno/CategoryWoman.html

Crabtree A, 2000 "Re: Post from Manny Schegloff, CA orthography, Sacks, etc.", Ethno E-mail List, Saturday 11th March, http://www.cios.org

Crabtree A, Nichols D M, Jon O B, Rouncefield M, Twidale M B, 1998 "The contribution of ethnomethodologically-informed ethnography to the process of designing digital libraries",

(Lancaster: University of Lancaster Technical Report CSEG/5/98) pp 28

Cresswell T, 1993 "Mobility as resistance: a geographical reading of Kerouac's On the Road"

Transactions of the Institute of British Geographers N.S. 18 249-262

De Certeau M, 1984 The Practice of Everyday Life (London: University of California Press)

Dix A, \& Beale, R., 1996 "Remote Cooperation: CSCW Issues for Mobile and Teleworkers", in

Computer Supported Cooperative Work Ed D Diaper, \& Sanger, C. (London: London)

Drew P, Heritage J, 1992 "Analysing talk at work", in Talk at work; interaction in institutional settings

Eds P Drew and J Heritage (Cambridge: Cambridge University Press) pp 3-65

Engestrom Y, 1990 When is a tool? Multiple meanings of artifacts in human acitivity (Helsinki:

Orienta-

Konsultit Oy)

Garfinkel H, 1967 Studies in Ethnomethodology (Englewood Cliffs, NJ: Prentice-Hall)

Garfinkel H, 1992 "Two Incommensurable, Asymmetrically Alternate Technologies of Social

Analysis", in Text in Context: Contributions to Ethnomethodology Eds G Watson and R M

Seiler (London: Sage) pp 175-206

Garfinkel H, Sacks H, 1970 "On Formal Structures of Practical Actions”, in Theoretical Sociology:

Perspectives and Developments Eds J C McKinney and E A Tiryakian (New York: Appleton-

Century-Crofts) pp 337-366

Gilroy P, 1993 The Black Atlantic: Modernity and Double Consciousness (London: Verso)

Goffman E, 1956 The Presentation of Self in Everyday Life (Edinburgh: Edinburgh University Press)

Guattari F, 1992 "Regimes, Pathways, Subjects" Zone 4 44-69 
Hastrup K, Olwig K F, 1997 Siting Culture: the Shifting Anthropological Object (London: Routledge) Have P T, 1998 Doing Conversational Analysis: a practical guide (London: Sage)

Heritage J C, Atkinson J M, 1984 "Introduction", in Structures of social action: studies in conversation analysis Eds J C Heritage and J M Atkinson (Cambridge: Cambridge) pp 1-15

Hinchliffe S, 1996 "Technology, power and space - the means and ends of geographies of technology" Environment and Planning D: Society and Space 14 659-682

Hopper R, 1991 "Hold the Phone", in Talk \& Social Structure Eds D Boden and D H Zimmerman (Cambridge: Cambridge University Press) pp 217-231

Houtkoop-Steenstra H, 1991 "Opening Sequences in Dutch Telephone Conversations", in Talk \& Social Structure Eds D Boden and D H Zimmerman (Cambridge: Cambridge University Press) pp 232-250

Huberman A M, Miles M B, 1998 "Data Management and Analysis Methods", in Collecting and Intepreting Qualitative Materials Eds N K Denzin and Y S Lincoln (London: Sage) pp 179-210

Kaplan C, 1996 Questions of Travel, Postmodern Discourses of Displacement (London: Duke University Press)

Katz J E, 1999 Connections, Social and Cultural Studies of the Telephone in American Life (London: Transaction)

King V, Randall D, 1994 "Trying to keep the customer satisfied", in Proceedings of the 5th IFIP Conference on Women, Work, and Computerisation (Manchester) pp 67-86

Latour B, 1992 "Where are the Missing Masses? The Sociology of a Few Mundance Artefacts", in Shaping Technology/Building Society Ed W L Bijker, J. (London: MIT Press) pp 225-258

Latour B, 1999 Pandora's Hope, Essays on the Reality of Science Studies (London: Harvard University Press)

Laurier E, 1998 "Geographies of talk: 'max left a message for you." Area 31 35-48

Laurier E, Goodwin N, Mckie L, 1999 "Smoking Cessation and the Notion of 'Benefit': Eliciting the Smoker's Agenda", (Aberdeen, UK: University of Aberdeen, Dept. of General Practice \& Primary Health Care CSO Final Report) pp 28

Luff P, Heath C, 1998 "Mobility in Collaboration", in Computer Supported Co-operative Work (CSCW) 98 (Seattle, WA: ACM Publications) pp 305-314

Lynch M, 1993 Scientific practice and ordinary action: ethnomethodology and social studies of science (Cambridge: Cambridge University Press)

Lynch M, 1997 "The Ethnomethodological Foundations of Conversation Analysis", in Ethnomethodology, an improbable sociology? (Cerisy-la-Salle, France: Copies available from the author)

Moerman M, 1988 Talking Culture: Ethnography and Conversation Analysis (London: Sage)

Mol A, Law J, 1994 "Regions, Networks and Fluids: Anaemia and Social Topology" Social Studies of Science 24 641-671

Morris M, 1988 "Banality in Cultural Studies" Block 14 15-26

Ochs E, Schegloff E A, Thompson S A, 1997 Interaction and grammar (Cambridge: Cambridge University Press)

Psathas G, 1991 "Direction-giving in Interaction”, in Talk \& Social Structure Ed D Boden (Cambridge: Cambridge University Press) pp 195-216

Psathas G, 1999 "Studying the Organization in Action: Membership Categorization and Interaction Analysis" Human Studies 22 139-162

Randall D, Hughes J, A., 1994 “Sociology, CSCW and Working with Customer", in Social and Interactional Dimensions of System Design Ed P Thomas (Cambridge: Cambridge University Press) pp check

Richards T J, Richards L, 1998 “Using Computers in Qualitative Research”, in Collecting and 
245

Interpreting Qualitative Materials Eds N K Denzin and Y S Lincoln (London: Sage) pp 211-

Ronell A, 1989 The Telephone Book: technology, schizophrenia electric speech (London: University of Nebraska Press)

Sacks H, 1972a "An initial investigation of the usability of conversational data for doing sociology", in Studies on social interaction Ed D Sudnow (New York: Free Press) pp 31-74

Sacks H, 1972b "Notes on Police Assessment of Moral Character", in Studies in Social Interaction Ed

D Sudnow (Glencoe: Free Press) pp 280-93

Sacks H, 1974 "On the Analysability of Stories by Children”, in Ethnomethodology Ed R Turner

(Harmondsworth: Penguin) pp 216-232

Sacks H, 1992a Lectures on conversation, Vol. 1 (Oxford: Blackwell)

Sacks H, 1992b Lectures on Conversation, Vol. 2 (Oxford: Blackwell)

Schatzki T R, 1996 Social Practices: A Wittgensteinian Approach to Human Activity and the Social

(Cambridge: Cambridge University Press)

Schegloff E, 1987 "Between Micro and Macro: Contexts and Other Connections", in The Micro-Macro

Link Eds J Alexander, B Giesen, R Munch and N Smelser (Berkeley CA: University of

California Press) pp 207-234

Schegloff E A, 1972a "Notes on a Conversational Practice: Formulating Place", in Studies in Social

Interaction Ed D Sudlow (Glencoe: Free Press) pp 75-119, 432-3

Schegloff E A, 1972b "Sequencing in Conversational Openings", in Directions in Sociolinguistics: The Ethnography of Communication Eds J J Gumperz and D Hymes (New York: Holt, Rhinehart \& Wilson) pp 346-80

Schegloff E A, 1978 "On some questions and ambiguities in conversation", in Current trends in linguistics Ed W U Dressler (Berlin: De Gruyter) pp 81-102

Schegloff E A, 1979 "Identification and Recognition in Telephone Conversation Openings", in Everyday Language: Studies in Ethnomethodology Ed G Psathas (New York: Irvington) pp 2378

Schegloff E A, 1992 "In another context", in Rethinking context: Language as an interactive phenomenon Ed A Duranti, \& Goodwin, C. (Cambridge: Cambridge) pp 191-228

Sharrock W, Coleman W, 1999 "Seeking and Finding Society in the Text", in Media Studies : Ethnomethodological Approaches Ed P L Jalbert (New York: University Press of America)

Suchman L, 1987 Plans and Situated Actions : The Problem of Human-Machine Communication (Cambridge: Cambridge University Press)

Suchman L, Jordan B, 1990 "Interactional troubles in face-to-face survey interviews" Journal of the American Statistical Association 85 232-241

Sudnow D, 1978 Ways of the Hand, The Organization of Improvised Conduct (London: MIT Press)

Thrift N, 1996 Spatial Formations (London: Sage)

Thrift N, 1999 "Steps to an Ecology of Place", in Human Geography Today Eds D Massey, J Allen and P Sarre (Oxford: Polity Press) pp 295-322

Tolmie P, Hughes J, Rouncefield M, Sharrock W, 1998 "Managing Relationships - Where the 'Virtual' meets the 'Real"', paper presented at the European Association for Studies of Science and Technology (Edinburgh) http://www.lancaster.ac.uk/sociology/ hughes/

Wenger E, 1998 Communities of Practice, Learning, Meaning \& Identity (Cambridge: Cambridge University Press)

Wittgenstein, L. 1953 Philosophical investigations (Oxford: Blackwell)

Wittgenstein, L. 1958 The Blue and Brown Books (New York: Harper and Row)

Zimmerman, D. H. 1992 'Achieving Context, Openings in Emergency Calls', in G. Watson and R. M. Seiler (eds) Text in Context: Contributions to Ethnomethodology (London: Sage) 